\title{
Combustion of Han-Based Liquid Monopropellants Near the Thermodynamic Critical Point
}

\author{
M. E. KOUNALAKIS and G. M. FAETH \\ Department of Aerospace Engineering, The University of Michigan, Ann Arbor, MI 48109-2140
}

\begin{abstract}
The high-pressure combustion properties of liquid monopropellants involving mixtures of hydroxyl ammonium nitrate (HAN), triethanol ammonium nitrate (TEAN), and water are considered theoretically. Liquid surface properties and the critical combustion pressure (the pressure required for the propellant surface to exceed its thermodynamic critical point) were found allowing for real-gas phenomena and the presence of dissolved combustion product gases in the liquid. Critical combustion pressures for the HAN-based monopropellants were found to be unusually high, ca. $2500 \mathrm{~atm}$, with an estimated uncertainty of $50 \%$. Predictions were unusually sensitive to the critical temperature of TEAN and the binary interaction parameter between TEAN and water; both must be known more accurately for definitive estimates of the liquid-surface properties of HAN-based monopropellants at high pressures.
\end{abstract}

\section{NOMENCLATURE}

c molar concentration

$d$ droplet diameter

$D$ effective binary diffusivity

$h_{i} \quad$ partial enthalpy of species $i$

$k_{i j}$ binary interaction parameter

$\dot{n}^{\prime \prime}$ total molar flux

$p$ pressure

Pr Prandtl number

$R$ gas constant

Re Reynolds number

Sc Schmidt number

$T$ temperature

$u \quad$ streamwise velocity

$v \quad$ specific volume

$x$ distance

$Y_{i} \quad$ mole fraction of species $i$

$\alpha \quad$ thermal diffusivity

$\delta \quad$ characteristic convection thickness

$\epsilon_{i} \quad$ mole flux fraction of species $i$

$\lambda$ mixture thermal conductivity

$\omega$ acentric factor

\author{
Subscripts \\ c thermodynamic critical point \\ f flame condition \\ $R$ reactant \\ o far-upstream condition
}

\section{INTRODUCTION}

The combustion of liquid monopropellant sprays involves pressure-atomized injection of the liquid into a high-pressure and high-temperature environment for typical applications, e.g., gas generators and regenerative liquid-propellant guns. After injection, the surfaces of ligaments, drops, etc., become heated, the propellant vaporizes and, finally, reacts to combustion products in the gas phase. At sufficiently high pressures, however, liquid surfaces approach the thermodynamic critical point, causing transition to the supercritical combustion regime at the critical combustion pressure. The process is equivalent to the singlephase premixed combustion of a dense gas within 
the supercritical combustion regime, and liquid surfaces are no longer observed. Clearly, it is important to know critical combustion pressures and liquid surface properties to define the pressure range where sprays are observed and to find spray properties within this regime. Analysis was undertaken to find these properties for hydroxyl ammonium nitrate-based monopropellants during the present investigation. HAN-based monopropellants are of interest because they are being considered for several high-pressure monopropellant combustion systems [1].

Near-critical phenomena of high-pressure liquid combustion has been studied earlier in this laboratory [2-7]. Various liquid monopropellants, such as nitrate esters [2], ethylene oxide [3], and hydrazine [4] were studied in strand combustion configurations, by analyzing gas phase transport using the thin flame approximation. High-pressure phenomena, such as real-gas effects and the presence of gaseous combustion products dissolved in the liquid phase, were treated using the Redlich-Kwong equation of state [8]. Predictions generally agreed with measured liquid surface temperatures, within uncertainties anticipated due to limitations concerning the high-pressure thermophysical and transport properties of combusting monopropellant systems [2-4]. Critical combustion pressures were in the range 100-200 atm for the nitrate ester monopropellants (normal propyl nitrate, ethyl nitrate, and propylene glycol dinitrate) [2] and ethylene oxide [3], which is typical of other liquid combustion processes that have been studied [5-7]. These predictions were relatively sensitive to values of transport properties and had estimated uncertainties of $30 \%$. Unfortunately, experimental evaluation of predicted critical combustion pressures was not possible, due to the appearance of unstable combustion waves associated with the loss of the stabilizing effect of surface tension near the thermodynamic critical point $[2,3]$ as the critical combustion pressure was approached.

Similar studies of the liquid surface properties of HAN-based monopropellants have not been reported, although McBratney $[9,10]$ has measured the strand burning rates of some typical blends. A liquid surface was clearly observed at
$290 \mathrm{~atm}$, while jelled samples maintained stable combustion surfaces up to $600 \mathrm{~atm}$. These findings suggest significantly higher critical combustion pressures for HAN-based monopropellants than for other monopropellants studied thus far; however, the presence of a jell complicates the interpretation of these results. The results also indicate that measurements of the liquid surface properties of HAN-based monopropellants would be very difficult. First, the burning rates of HANbased monopropellants are on the order of $20 \mathrm{~mm}$ $s^{-1}[9,10]$, which is an order of magnitude faster than other propellants that have been studied [2, 3]. Such burning rates imply characteristic flame thicknesses, $\alpha / u$ for each phase, and characteristic flame residence times, $\alpha / u^{2}$ for each phase, on the order of $1 \mu \mathrm{m}$ and $1 \mu \mathrm{s}$ based on typical transport properties. Thus, adequate resolution and response for surface temperature measurements, or even for distinguishing a liquid surface in such a thin flame zone, is unlikely. Finally, past attempts to measure critical combustion pressures, or liquid surface properties near the thermodynamic critical point, have not been successful $[2,3]$.

In view of the experimental problems, theory was used to find liquid surface properties and critical combustion pressures during the present investigation. Earlier theoretical methods [2-4] were extended to treat the specific features of some representative HAN-based monopropellants. Predictions require thermophysical and transport properties that must be estimated for monopropellants; therefore, the effects of these uncertainties were evaluated using sensitivity analysis. The study was limited to two HAN-based monopropellants, LGP 1845 and LPG 1846, which are mixtures of HAN, triethanol ammonium nitrate, and water. These choices were made because McBratney studied LGP 1845 [10], because recent spray studies have used LGP 1846 [1], and because similar formulations are candidates for practical applications.

\section{THEORY}

\section{General Description}

The theory is an extension of the approach used in [3]. Phase equilibrium considerations were im- 
proved by considering the more highly developed modified Redlich-Kwong equation of state due to Soave $[11,12]$, as well as the basic RedlichKwong equation of state [7] used by this laboratory in earlier work $[2,3]$. The earlier methods were developed for the analysis of monopropellant strand combustion $[2,3]$; the relevance of this approach for estimating liquid surface properties and critical combustion pressures in sprays was also considered.

As in past work [2-4], the combustion process was assumed to be a steady, laminar one-dimensional deflagration wave. Typical combusting spray conditions involve pressures greater than 10 $\mathrm{MPa}$ and drops or other liquid elements having diameters or radii of curvature greater than $10 \mu \mathrm{m}$, because smaller liquid elements approximate the dynamics of the gas phase in any event [13]. Under these conditions, pressure drops across the wave are less than $100 \mathrm{~Pa}$ even for the high burning rates of the HAN-based propellants; therefore the approximation of a constant-pressure deflagration wave can be adopted with little error. Based on the burning rate measurements of McBratney $[9,10]$, combustion lifetimes of the liquid elements of interest are greater than $1 \mathrm{~ms}$, which is much greater than the estimated characteristic residence time $(1 \mu \mathrm{s})$ in the wave; therefore, the steady (quasisteady) wave approximation is appropriate as well.

Forced convection and turbulence in sprays can cause departures from one-dimensional waves near liquid surfaces. Multidimensional effects due to forced convection are small when the characteristic convection thickness is greater than the characteristic flame thickness [14]. The convection thickness for drops can be estimated with sufficient accuracy for present purposes as follows [13]

$\delta=d /\left(2+0.556 \operatorname{Re}^{\frac{1}{2}}(\operatorname{Pr} \text { or Sc })^{\frac{1}{3}}\right)$.

Maximum drop Reynolds numbers in sprays are on the order of $10^{2}$ [13]; therefore, Eq. 1 implies that characteristic convection thicknesses are greater than the $1-\mu \mathrm{m}$ characteristic flame thickness of present propellants for drop diameters greater than $10 \mu \mathrm{m}$. Existing information on the length microscales of turbulence in spray flames is very limited; however, one estimate for the fully developed portion of sprays having a typical Reynolds number of $10^{4}$ suggests that the microscales are on the order of $10^{-3}$ times the distance from the injector [13]. This implies that microscales are greater than the characteristic flame thickness for distances greater than $1 \mathrm{~mm}$ from the injector exit; therefore, turbulence should have little effect on the one-dimensionality of flame properties for most portions of monopropellant spray flames. Based on these considerations, the assumption of one-dimensional laminar flow appears to be relevant for spray combustion of the present monopropellants.

Combustion was assumed to be adiabatic with thermodynamic equilibrium reached at the downstream edge of the reaction zone, which are reasonable assumptions for high-intensity spray combustion at high pressures. The properties of the combustion products were computed under these assumptions using the Gordon and McBride code [15]; results for LGP 1845 and LPG 1846 are summarized in Table 1 for pressures of $1 \mathrm{MPa}, 10$ $\mathrm{MPa}$, and $100 \mathrm{MPa}$. Both reactant mixtures are stoichiometric and have virtually identical combustion product compositions; the main difference between the two is that the flame temperature of LGP 1845 is roughly $100 \mathrm{~K}$ higher than that of LGP 1846. The combustion products are nearly $70 \%$ water vapor. Due to the relatively low combustion temperatures and high pressures, dissociation effects are small, and combustion product concentrations are nearly independent of pressure.

The propellants have relatively low flame temperatures; therefore, effects of radiation can be neglected. For example, if we conservatively assume that the emissivity of the combustion products is unity and that reabsorption between the flame and the liquid surface is negligible, the burning rate measurements of McBratney $[9,10]$ imply that radiation contributes less than $4 \%$ to the enthalpy rise of gasification of the liquid.

Precise treatment of combustion chemistry is not possible, because the mechanisms and rate constants are not known for the high-pressure decomposition of HAN-based monopropellants; 
TABLE 1

Combustion Properties of HAN-Based Monopropellants ${ }^{a}$

\begin{tabular}{|c|c|c|c|c|c|c|}
\hline \multirow{2}{*}{$\frac{\text { Propellant }}{\text { Pressure (MPa) }}$} & \multicolumn{3}{|c|}{ LGP $1845^{b}$} & \multicolumn{3}{|c|}{ LGP $1846^{c}$} \\
\hline & 1 & 10 & 100 & 1 & 10 & 100 \\
\hline \multicolumn{6}{|c|}{ Combustion product properties } & 1454 \\
\hline Density $\left(\mathrm{kg} \mathrm{m}^{-3}\right)$ & 1.30 & 12.9 & 129 & 1.36 & 13.5 & 135 \\
\hline Temperature (K) & 2133 & 2152 & 2163 & 2027 & 2039 & 2045 \\
\hline \multicolumn{7}{|c|}{ Composition (\% by volume) ${ }^{d}$} \\
\hline Water vapor & 68.8 & 69.2 & 69.3 & 70.6 & 70.8 & 70.9 \\
\hline Carbon dioxide & 12.7 & 12.9 & 13.0 & 12.2 & 12.3 & 12.3 \\
\hline Nitrogen & 17.3 & 17.4 & 17.4 & 16.5 & 16.5 & 16.6 \\
\hline
\end{tabular}

adiabatic, constant pressure combustion, with the liquid reactant at $298.15 \mathrm{~K}$.

${ }^{b}$ Reactant composition (\% by mass): HAN, 63.2; TEAN, 20 ; and $\mathrm{H}_{2} \mathrm{O}, 16.8$.

c Reactant composition (\% by mass): $\mathrm{HAN}, 60.8$; TEAN, 19.2; and $\mathrm{H}_{2} \mathrm{O}, 20.0$.

${ }^{d}$ Major species only. Minor species include: $\mathrm{CO}, \mathrm{H}_{2}, \mathrm{NO}, \mathrm{OH}$, and $\mathrm{O}_{2}$.

therefore, the limiting approximation of an infinitely thin gas phase reaction zone located at some distance from the liquid surface was made, as in past work [2-4]. This large activation energy limit is favored for the present monopropellants due to their relatively low flame temperatures.

Consistent with the thin flame approximation, liquid phase reactions were also ignored. This is favored by the very short residence times in the high-temperature portions of the liquid phase, ca. 100 ns. Typical unimolecular decomposition reactions, which are at least representative of the first stage of reaction in the liquid, have characteristic reaction times two or more orders of magnitude longer than the liquid residence time for present conditions, providing some justification for this assumption.

Phase equilibrium was assumed at the liquid surface, as in past work [2-4]. This is a good approximation for drop diffusion flames at pressures greater than 0.1 MPa [12]; however, the assumption was reexamined due to the high burning rates of the HAN propellants. Following Dunn and Reay [16], the burning rate measurements of McBratney $[9,10]$ imply differences between actual and saturated vapor pressures at the liquid surface less than $0.3 \mathrm{MPa}$ due to finite rates of evaporation. This is clearly small in comparison to the combustion pressures of interest, which were greater than $10 \mathrm{MPa}$. The corresponding temperature jumps at the surface, due to finite evaporation rates, were found using the present phase equilibrium analysis. The resulting temperature jumps were less than $0.3 \mathrm{~K}$, which is also small in comparison to the temperature rise in the liquid phase. Thus, phase equilibrium at the surface can be adopted with little error.

Gas phase transport was treated similar to earlier analyses of liquid combustion processes at high pressures [2-7]. Only concentration diffusion was considered, taking the binary diffusivities of all species to be equal, and neglecting the Dufour energy flux. The assumption of an effective binary diffusion coefficient is more questionable for blends like the HAN-based propellants than for blends studied in earlier work where only a single species was diffusing and the approximation was exact. However, the present approach seems reasonable in view of the other approximations of the analysis; the effect of the approximation was examined by sensitivity calculations. The specific treatment of thermophysical and transport properties will be discussed later. Effects of compressibility and varying Lewis numbers were consid- 
ered, particularly because variations in the Lewis number are known to influence predictions of critical combustion pressures [2-7].

Monopropellants typically have negligible dissolved gas concentrations prior to injection; therefore, carbon dioxide and nitrogen are not present in the bulk liquid and have negligible mass fluxes upstream of the flame. However, the propellant components HAN, TEAN, and water, all have finite mass fluxes upstream of the flame, the last being both a propellant component and a combustion product.

\section{Transport Analysis}

Because only liquid surface properties are of interest (not burning rates), the equations to be solved are identical in all one-dimensional coordinate systems: Cartesian for large liquid elements, cylindrical for ligaments, and spherical for drops. A Cartesian formulation, sketched in Fig. 1, is used to simplify the notation. The analysis is confined to the region between the flame and liquid surface, corresponding to the outer region of asymptotic analysis of monopropellant flames at the high activation energy limit. Effects of multicomponent diffusion and the presence of dissolved gases cause reactant (HAN and TEAN) concentrations to vary in the liquid phase. There is a concentration jump at the liquid surface, dictated by phase equilibrium requirements. The corresponding temperature jump is small, however, as noted earlier. Properties at the flame surface are

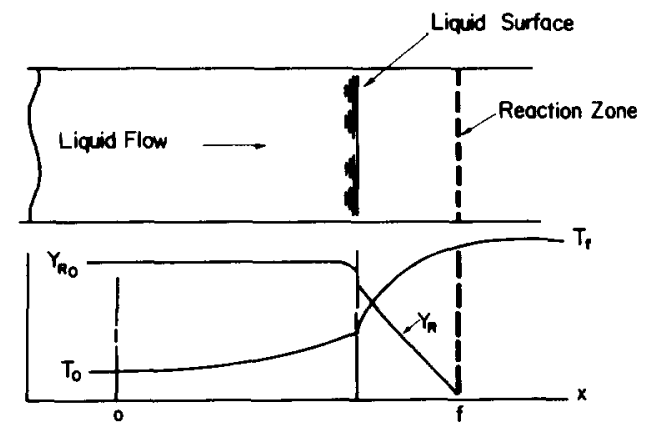

Fig. 1. Sketch of the liquid monopropellant combustion process. given by the adiabatic flame calculations discussed earlier, see Table 1.

Gas phase transport was formulated in terms of molal quantities to simplify matching with the phase equilibrium analysis. Under present assumptions, the equations governing conservation of energy and species between the liquid surface and the flame sheet are as follows [2-4]

$\dot{n}^{\prime \prime} \sum_{i=1}^{N} \epsilon_{i}\left(h_{i}-h_{i 0}\right)=\lambda \frac{\mathrm{d} T}{\mathrm{~d} x}$

$\dot{n}^{\prime \prime}\left(Y_{i}-\epsilon_{i}\right)=c D \frac{\mathrm{d} Y_{i}}{\mathrm{~d} x}, i=1, \cdots, N$.

Initial conditions for Eqs. 2 and 3 can be specified in terms of known flame properties as follows

$x=x_{\mathrm{f}}, T=T_{\mathrm{f}}, Y_{i}=Y_{i \mathrm{f}}, i=1, \cdots, N$.

Denote the species present in the original monopropellant as $i=1, \cdots, R<N$. Then, eliminating spatial derivatives among Eq. 3, integrating, and applying the concentration boundary conditions of Eq. 4 yields

$Y_{i}=\epsilon_{i}+\frac{\left(Y_{i \mathrm{f}}-\epsilon_{\mathrm{i}}\right)\left(Y_{j}-\epsilon_{j}\right)}{\left(Y_{j \mathrm{f}}-\epsilon_{j}\right)}$

where $i \neq j$, and $j$ can be any species $j=1, \cdots$ $R$.

Eliminating spatial derivatives between Eq. 2 and Eq. 3 for $i=j$ yields

$$
\frac{\mathrm{d} Y_{j}}{\mathrm{~d} T}=-\frac{(\lambda / c D)\left(\epsilon_{j}-Y_{j}\right)}{\sum_{i=1}^{N} \epsilon_{i}\left(h_{i}-h_{i 0}\right)}
$$

where $j$ is selected in the same manner as Eq. 5 . The initial condition for Eq. 6 is

$T=T_{\mathrm{f}}, Y_{j}=Y_{j \mathrm{f}}$.

As noted earlier, the effects of pressure on flame properties were small; therefore, a single flame condition was used for each propellant. These properties, as well as the $\epsilon_{i}$ that are fixed by the propellant composition, are summarized in Table 2 for each propellant. 
TABLE 2

Mole Flux Fractions and Flame Properties for Calculations

\begin{tabular}{lrr}
\hline \multicolumn{1}{c}{ Fuel } & LGP 1845 & LGP 1846 \\
\hline Mole Flux Fractions (\%) & & \\
HAN & 39.1 & 34.5 \\
TEAN & 5.6 & 4.9 \\
$\quad \mathrm{H}_{2} \mathrm{O}$ & 55.3 & 60.6 \\
Flame Properties: & & \\
$\quad$ Temperature (K) & 2146 & 2040 \\
Composition (\% by volume): & & \\
$\quad \mathrm{H}_{2} \mathrm{O}$ & 69 & 71 \\
$\mathrm{CO}_{2}$ & 13 & 12 \\
$\mathrm{~N}_{2}$ & 18 & 17 \\
\hline
\end{tabular}

Given Eq. 5 and mixture properties as a function of temperature and pressure, Eq. 6 can be integrated from the flame toward the liquid surface, providing the transport locus of the variation of species mole fractions with temperature. Liquid surface conditions are reached when the properties along the transport locus reach a dew point of the phase equilibrium analysis. Dew-point computations are considered next.

\section{Phase Equilibrium Analysis}

Two methods were used to compute phase equilibrium at the liquid surface: the Redlich-Kwong equation of state with mixing rules developed by Prausnitz and Chueh [8], which was used during earlier studies of high-pressure liquid combustion [2-7]; and the more highly developed modified Redlich-Kwong equation of state due to Soave
$[11,12]$. The use of these equations of state for polar compounds like HAN, TEAN, and water is tentative, for lack of a viable alternative. Prausnitz et al. [17] found, however, that polar corrections of the equation of state are small when reduced temperatures are greater than 0.95 ; this condition was generally satisfied for the most polar compounds during present computations.

Phase equilibrium at the liquid surface requires that the temperature, pressure, and fugacity of each species is the same in both phases. Given the pressure and the gas phase composition along the transport locus, the corresponding liquid phase composition and equilibrium temperature can be computed from the equation of state. This corresponds to a dew-point calculation, using the computer codes found in [11] and [7] for the Soave and Relich-Kwong equations of state. Liquid surface conditions are reached when the transport and phase equilibrium temperatures are the same.

\section{Thermophysical Properties}

The equations of state require critical properties and acentric factors, while computations of flame properties require enthalpies of formation. The values of these properties used during the calculations are summarized in Table 3 . The properties of $\mathrm{H}_{2} \mathrm{O}, \mathrm{CO}_{2}$, and $\mathrm{N}_{2}$ listed in this table are drawn from standard references $[18,19]$, and present no problems.

HAN and TEAN decompose at high temperatures; therefore, their thermophysical properties must be estimated. The Lyderson method $[20,21]$

TABLE 3

Thermophysical Properties

\begin{tabular}{|c|c|c|c|c|c|}
\hline Species & HAN & TEAN & $\mathrm{H}_{2} \mathrm{O}$ & $\mathrm{CO}_{2}$ & $\mathbf{N}_{2}$ \\
\hline \multicolumn{6}{|l|}{ Critical Properties } \\
\hline Temperature (K) & 763 & 1294 & 647.3 & 304.2 & 126.2 \\
\hline Pressure (atm.) & 76 & 36 & 217.6 & 72.8 & 33.5 \\
\hline Volume $\left(\mathrm{cm}^{3} / \mathrm{gmol}\right)$ & 196 & 528 & 56 & 94 & 89.5 \\
\hline Acentric factor & 0.68 & 1.41 & 0.344 & 0.225 & 0.040 \\
\hline $\begin{array}{l}\text { Enthalpy of formation } \\
\text { at } 298.15 \mathrm{~K}\left(\mathrm{kcal}_{\mathrm{gmol}}{ }^{-1}\right)\end{array}$ & -95.3 & -185.5 & -57.8 & -94.0 & 0.0 \\
\hline
\end{tabular}


was used to estimate the critical pressure, the critical volume, and the ratio of the normal boiling and critical temperatures. Acentric factors were computed from their definition, using the Lee and Kesler generalized vapor-pressure relationship [22]. The critical temperature was then computed from the Lee and Kesler expression [22] for the compressibility factor, applied at the critical point, as follows

$$
T_{\mathrm{c}}=\left(p_{\mathrm{c}} v_{\mathrm{c}} / R\right) /(0.291-0.080 \omega)
$$

These methods are routinely used for hydrocarbons, but they have not been tested for compounds like HAN and TEAN. Thus, the approach was evaluated by applying it to a variety of organic and inorganic compounds whose critical properties and acentric factors were known: $\mathrm{NH}_{3}, \mathrm{CO}_{2}$, $\mathrm{H}_{2} \mathrm{O}, \mathrm{SO}_{2}, \mathrm{NO}_{2}, n$-hexanol, benzyl alcohol, $n$, $n$-dimethylaniline, $n$-hexadecane, $n$-eicosane, and $n$-butanol. The average errors were as follows: critical temperature, $-5 \%$; critical pressure, $-2.5 \%$; critical volume, $-9.6 \%$; and the acentric factor, $0.6 \%$. Based on these findings, the approach appears to be reasonable for present purposes.

The enthalpies of formation of HAN and TEAN listed in Table 3 were found using the Verma and Doraiswamy group contribution method [23]. Uncertainties in these properties are not very important, however, because flame properties are dominated by the enthalpies of formation of $\mathrm{H}_{2} \mathrm{O}$, $\mathrm{CO}_{2}$, and $\mathrm{N}_{2}$, which are well known $[18,19]$.

Ideal-gas enthalphy changes with temperature were found from standard sources for $\mathrm{H}_{2} \mathrm{O}, \mathrm{CO}_{2}$, and $\mathrm{N}_{2}[18,19]$. The group contribution specific heat correlation of Rihani and Doraiswamy [24] was used to compute ideal-gas enthalpy changes for HAN and TEAN. Enthalpy deviations and $c$ were found directly from the equations of state.

Binary interaction parameters $k_{i j}$ are used in the equations of state. Present values of the $k_{i j}$ are summarized in Table 4 . These estimates were found from $[11,12]$ for the Soave equation of state, and from [5, 8] for the Redlich-Kwong equation of state. Measurements of $k_{i j}$ are not available for binary pairs involving HAN and TEAN; therefore, the values for the hydrocarbon
TABLE 4

Binary Interaction Parameters $\left(k_{i j}\right)^{\text {q }}$

\begin{tabular}{cccr}
\hline Substance & $\mathrm{H}_{2} \mathrm{O}$ & $\mathrm{CO}_{2}$ & \multicolumn{1}{c}{$\mathrm{N}_{2}$} \\
\hline \multicolumn{4}{c}{ Soave equation of state } \\
$\mathrm{HAN}$ & 0.381 & 0.136 & 0.140 \\
TEAN & 0.368 & 0.138 & 0.164 \\
$\mathrm{H}_{2} \mathrm{O}$ & 0.000 & 0.102 & 0.140 \\
$\mathrm{CO}_{2}$ & 0.102 & 0.000 & -0.022 \\
& Redlich-Kwong equation of state \\
HAN & 0.385 & 0.285 & 0.335 \\
TEAN & 0.790 & 0.650 & 0.745 \\
\hline
\end{tabular}

${ }^{a} k_{i i}=0 ; k_{i j}=k_{j i}$; other interaction parameters not shown were taken to be zero. The systems were modeled by homomorphs.

homomorphs of these species were used, as in past work [2-7].

\section{Transport Properties}

Mixture thermal conductivities and effective binary diffusivities are needed to integrate Eq. 6 . Correlations of mixture thermal conductivities require the viscosities of all species as well. Idealgas thermal conductivities and viscosities were taken from Svehla [25] for $\mathrm{H}_{2} \mathrm{O}, \mathrm{CO}_{2}$, and $\mathrm{N}_{2}$, while the Eucken model [25] and the Reichenberg method [26] were used to estimate these properties for HAN and TEAN. Ideal gas mixture thermal conductivities were then found from the Wassiljewa equation [27], following Lindsay and Bromley [26]. The effect of compressibility on the mixture's thermal conductivity was determined by the Stiel and Thodos method [29], using the Prausnitz and Gunn rules for mixture pseudocritical properties [18].

Low-pressure binary diffusivities were found for all binary pairs in the system using the method of Fuller, Schettler and Giddings [30, 31] based on the average of these values at each temperature. The effect of compressibility on the effective binary diffusivity was computed following Dawson et al. [32], using the Prausnitz and Gunn modified rules for mixture pseudocritical properties [18], as before. 


\section{RESULTS AND DISCUSSION}

\section{Critical Combustion Conditions}

Results for LGP 1845 and LPG 1846 were very similar, in view of property uncertainties; therefore, findings for LGP 1845 will be taken as representative in the following.

The nature of the solution for liquid surface properties, in the vicinity of the thermodynamic critical point, can be seen by reference to Fig. 2 . Transport and phase equilibrium loci are plotted as functions of the gas phase mole fraction of HAN and the temperature at various pressures. The phase equilibrium locus was found using the Soave equation of state with all $k_{i j}=0$; however, the properties of the plots are similar to findings for the range of $k_{i j}$ considered during the investigation. Both loci satisfy Eq. 5, which relates the mole fractions of TEAN, $\mathrm{H}_{2} \mathrm{O}, \mathrm{CO}_{2}$, and $\mathrm{N}_{2}$ to the mole fraction of HAN in the gas phase. In addition, the transport locus satisfies the conservation of energy requirements of Eq. 6, while the phase equilibrium locus satisfies the requirements of thermodynamic equilibrium at the liquid surface. The intersection of these two loci, at a given pressure, is a solution for the gas phase properties at the liquid surface, where Eqs. 5 and 6 and the requirements for phase equilibrium are all satisfied.

At the lowest pressure illustrated in Fig. 2, 500 atm, the transport and phase equilibrium loci intersect, yielding a liquid-surface solution point. This behavior persists for all pressures below 640 atm. However, the transport locus becomes tangent to the phase equilibrium locus at $640 \mathrm{~atm}$; this is the highest pressure where a liquid surface is present for the conditions illustrated in Fig. 2, and it corresponds to the critical combustion pressure. Pressures greater than $640 \mathrm{~atm}$ are within the supercritical combustion regime where the transport and phase equilibrium loci no longer intersect, see the results illustrated in Fig. 2 for 650 atm. In this regime, flow properties simply vary along the transport locus until the initial conditions in the bulk liquid are reached, and a liquid surface is never observed.

\section{Liquid Surface Properties}

The properties of the liquid surface for the subcritical regime, using the same solution parameters as Fig. 2 (the Soave equation of state with all $k_{i j}=0$ ), are illustrated in Fig. 3. The surface temperature and species mole fractions in the gas and liquid phases are plotted as a function of pressure up to the critical combustion pressure.

Gas phase concentrations are relatively independent of pressure in Fig. 3; however, liquid phase concentrations vary substantially due to the presence of dissolved gases in the liquid at higher pressures. Other liquid combustion systems behave in a similar manner [2-7]. At low pressures, concentrations of dissolved combustion product gases $\left(\mathrm{CO}_{2}\right.$ and $\left.\mathrm{N}_{2}\right)$ are quite small, and the more

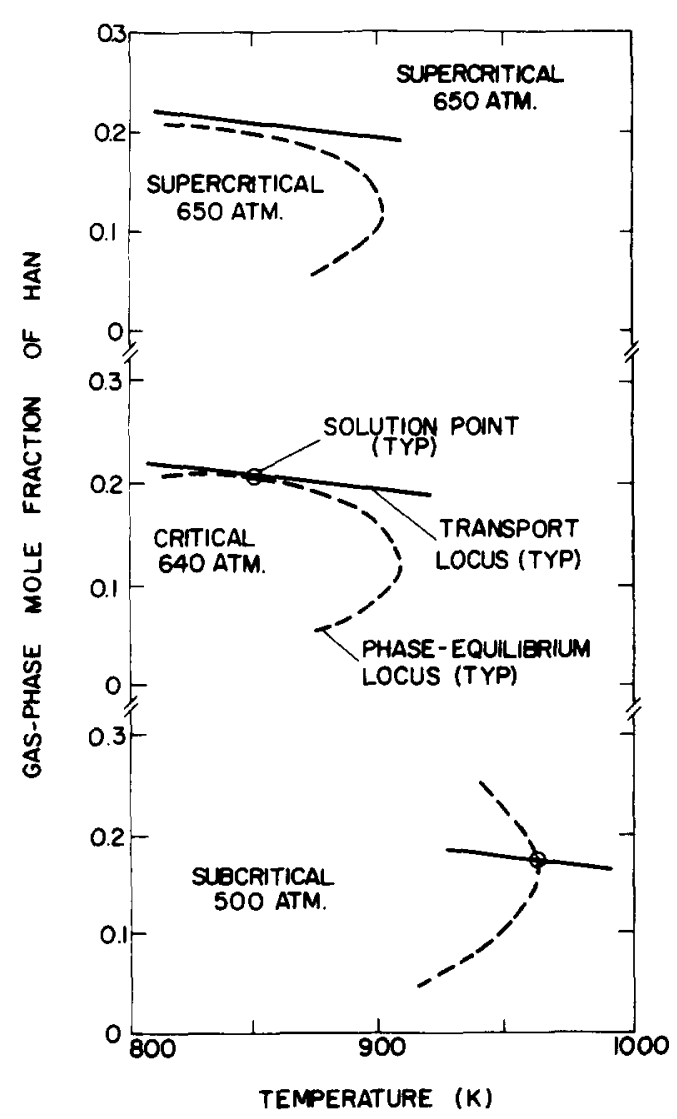

Fig. 2. Transport- and phase-equilibrium loci for subcritical, critical, and supercritical conditions; Soave equation of state, $\boldsymbol{k}_{i j}=\mathbf{0}$. 


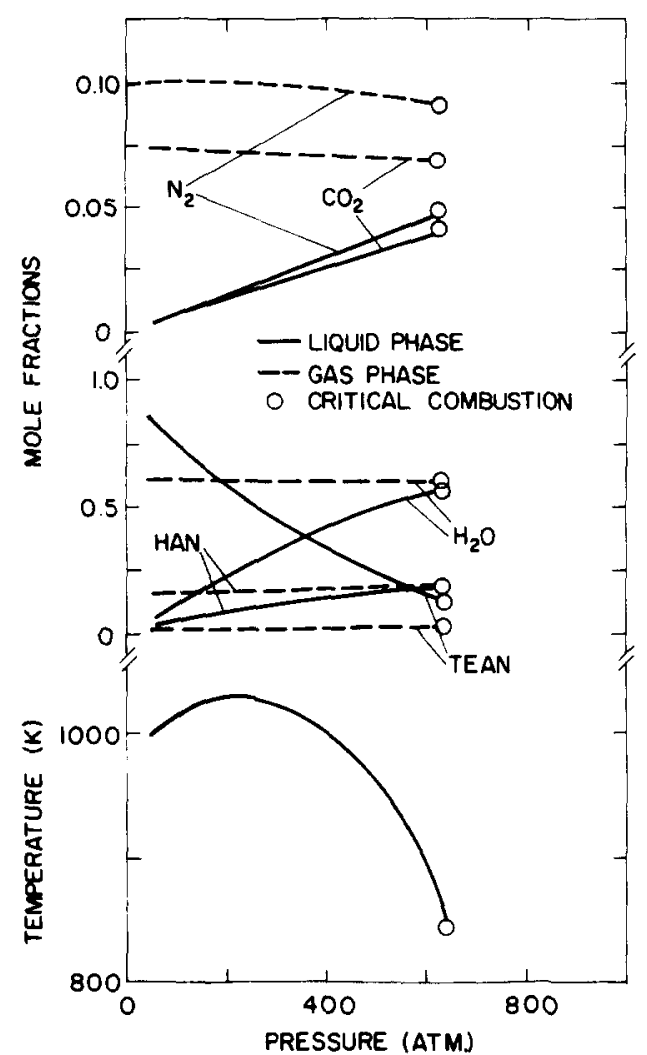

Fig. 3. Properties of the liquid surface as a function of pressure; Soave equation of state, $k_{i j}=0$.

volatile propellant components ( $\mathrm{HAN}$ and $\mathrm{H}_{2} \mathrm{O}$ ) are depleted in the liquid phase, leaving a high concentration (a mole fraction near 0.9 ) of the relatively nonvolatile TEAN. As the pressure is increased, however, concentrations of the more volatile components increase in the liquid, with water having the highest concentrations in the liquid for pressures greater than $400 \mathrm{~atm}$. Concentrations of the gas and liquid are not the same at the critical combustion condition, and neither are the enthalpies; therefore, the critical combustion condition does not correspond to a thermodynamic critical point in this case. Thus, while the critical combustion condition often is a thermodynamic critical point [2-7], such behavior is not always observed.

At low pressures, the surface temperatures plotted in Fig. 3 increase with increasing pressure, which is typical of the behavior of other monopro- pellants that have been studied [2-4]. However, the surface temperature reaches a maximum, and then declines as the critical combustion pressure is approached. Similar behavior has been observed for ethylene oxide [3]. The effect is due to the greater concentrations of more volatile species, which have relatively low critical temperatures, in the liquid phase at high pressures. Due to the relatively low volatility of HAN and TEAN, however, liquid surface temperatures are unusually high; e.g., peak temperatures approach 1000 $\mathrm{K}$ in Fig. 3, as opposed to $500 \mathrm{~K}$ for the nitrate esters and ethylene oxide [2, 3].

The best estimate of liquid surface properties for LGP 1845, using the Soave equation of state and the standard $k_{i j}$ values, is illustrated in Fig. 4.

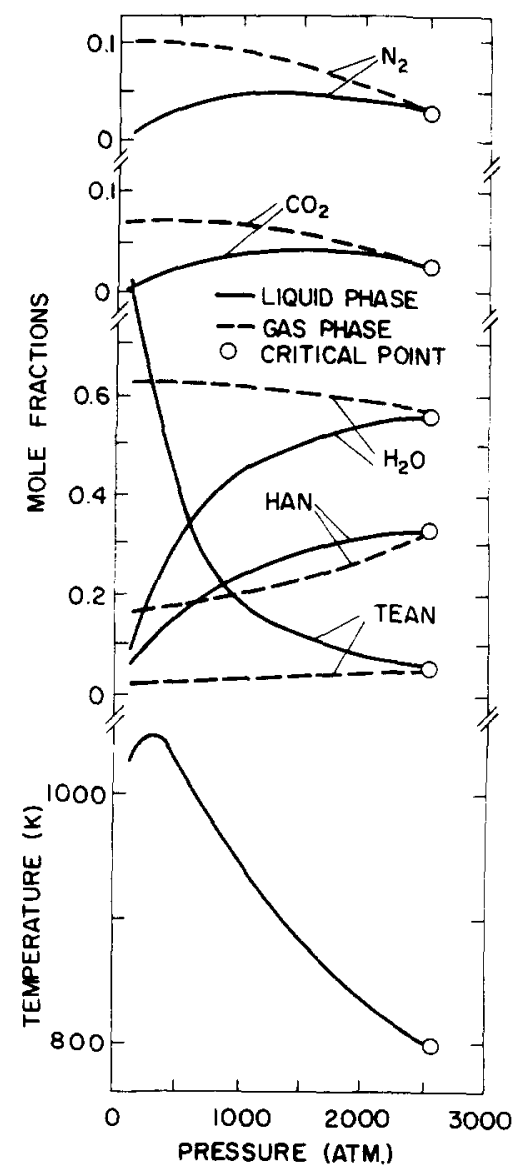

Fig. 4. Properties of the liquid surface as a function of pressure; Soave equation of state, standard $k_{i j}$. 
The change in the $k_{i j}$ causes a substantial increase in the predicted critical combustion pressure, from $640 \mathrm{~atm}$ for $k_{i j}=0$, to $2600 \mathrm{~atm}$ for the standard $k_{i j}$. Such strong effects of the $k_{i j}$ on liquid surface properties were not observed during earlier studies of liquid monopropellants [1-3]. For the results illustrated in Fig. 4, the critical combustion condition coincides with a thermodynamic critical point; this is indicated by the equality of gas and liquid compositions at the critical combustion pressure. Other differences when the standard $k_{i j}$ are used included a greater variation of gas phase compositions and higher concentrations of HAN in the liquid phase, cf., Figs. 3 and 4. However, the range of liquid surface temperatures and the presence of a peak temperature at low pressures are similar in Figs. 3 and 4.

The Soave equation of state was felt to be the most reliable, because the $k_{i j}$ values for the Redlich-Kwong equation of state were unusually high, and solutions with this approach were numerically very stiff. Nevertheless, results were obtained using the Redlich-Kwong equation of state, because it has been used for monopropellants in the past [2,3]. Liquid surface properties computed in this manner for LGP 1845 are illustrated in Fig. 5 using standard values of the $k_{i j}$. The main difference between the results using the Soave and Redlich-Kwong equations of state, cf. Figs. 3 and 4 , is that the latter yields a much higher critical combustion pressure, higher than the 4000-atm pressure range considered in Fig. 5. Thus, the results in Fig. 5 are similar to the lowpressure region of Fig. 4: the gas phase compositions are relatively independent of pressure; the liquid phase concentrations of the more volatile components $\left(\mathrm{CO}_{2}, \mathrm{~N}_{2}\right.$, and $\left.\mathrm{H}_{2} \mathrm{O}\right)$ increase with pressure; and the surface temperature increases with pressure. Predicted liquid surface temperatures become quite high as the pressure is increased, which, if true, raises concerns about potentially significant effects of reaction near the liquid surface.

\section{Sensitivity Analysis}

The equation of state and the values of the $k_{i j}$ clearly have a significant effect on predictions of

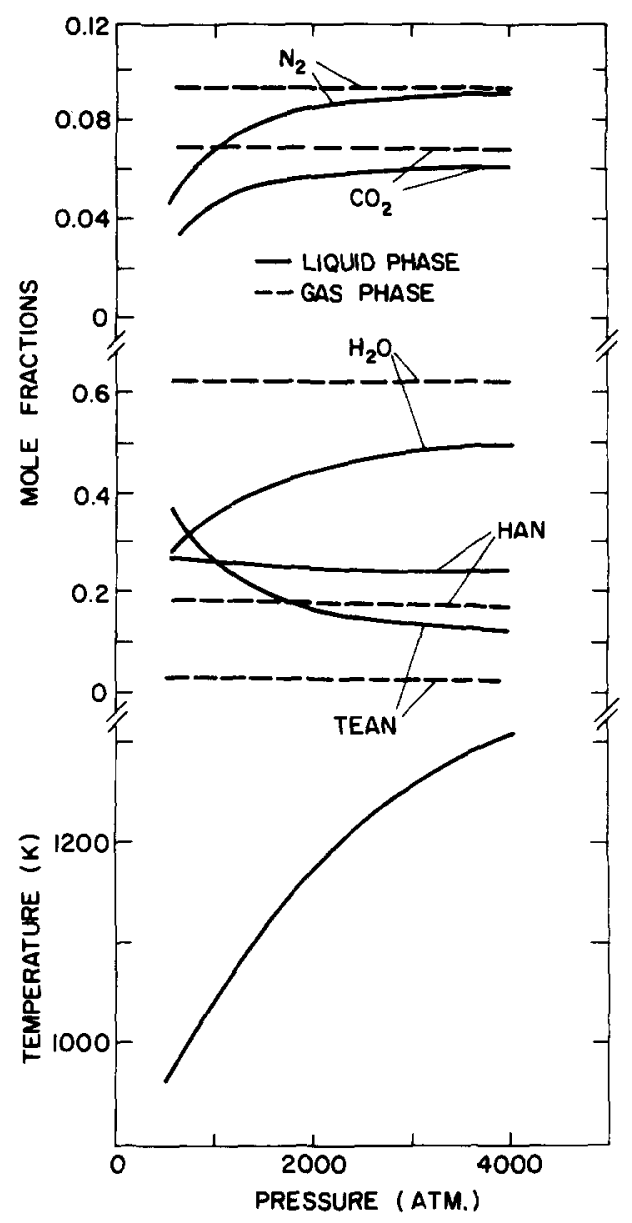

Fig. 5. Properties of the liquid surface as a function of pressure; Redlich-Kwong equation of state, standard $k_{i j}$.

liquid surface conditions and the critical combustion pressure. Sensitivity analysis was undertaken to more precisely identify parameters that have a strong influence on predictions. The baseline for the sensitivity calculations was the Soave equation of state with all $k_{i j}=0$. An exhaustive search procedure was used, where the effect of each parameter was evaluated independently.

Table 5 is a summary of the results of the sensitivity analysis, considering only the most sensitive parameters. The percent change in the critical combustion pressure, the critical combustion temperature, the pressure where the surface temperature is maximum, and the maximum surface temperature are given as a function of the percent change of the parameters (or the change in 
TABLE 5

Sensitivity Analysis (LGP 1845)

\begin{tabular}{|c|c|c|c|c|c|}
\hline $\begin{array}{l}\text { Output } \\
\text { variable }\end{array}$ & & $\begin{array}{l}\text { Critical } \\
\text { combustion } \\
\text { pressure } \\
(\mathbf{a t m})\end{array}$ & $\begin{array}{c}\text { Critical } \\
\text { combustion } \\
\text { temperature } \\
\text { (K) }\end{array}$ & $\begin{array}{c}\text { Pressure at } \\
\text { maximum } \\
\text { temperature } \\
\text { (atm) }\end{array}$ & $\begin{array}{c}\text { Maximum } \\
\text { temperature } \\
\text { (K) }\end{array}$ \\
\hline Standard Value ${ }^{a}$ & & 640 & 840 & 200 & 1030 \\
\hline Parameter $^{b}$ & Variation & \multicolumn{4}{|c|}{ Percent change } \\
\hline $\begin{array}{l}\text { Thermal } \\
\text { conductivity }\end{array}$ & $\begin{array}{l}+25 \% \\
-25 \%\end{array}$ & $\begin{array}{r}-18 \\
6\end{array}$ & $\begin{array}{r}10 \\
2\end{array}$ & $\begin{array}{l}0 \\
0\end{array}$ & $\begin{array}{l}\sim 0 \\
\sim 0\end{array}$ \\
\hline $\begin{array}{l}\text { Diffusion } \\
\text { coefficient }\end{array}$ & $\begin{array}{l}+25 \% \\
-25 \%\end{array}$ & $\begin{array}{r}6 \\
-18\end{array}$ & $\begin{array}{r}2 \\
10\end{array}$ & $\begin{array}{r}0 \\
-14\end{array}$ & $\begin{array}{l}\sim 0 \\
\sim 0\end{array}$ \\
\hline $\begin{array}{l}\text { Critical temperature } \\
\text { of TEAN }\end{array}$ & $\begin{array}{l}+10 \% \\
-10 \%\end{array}$ & $\begin{array}{r}44 \\
-34\end{array}$ & $\begin{array}{r}5 \\
-4\end{array}$ & $\begin{array}{r}0 \\
-25\end{array}$ & $\begin{array}{r}11 \\
-18\end{array}$ \\
\hline $\begin{array}{l}\text { Acentric factor } \\
\text { of TEAN }\end{array}$ & $\begin{array}{l}+20 \% \\
-20 \%\end{array}$ & $\begin{array}{r}13 \\
-18\end{array}$ & $\begin{array}{l}2 \\
2\end{array}$ & $\begin{array}{l}0 \\
0\end{array}$ & $\begin{array}{l}2 \\
2\end{array}$ \\
\hline $\begin{array}{l}k_{i j}{ }^{c} \\
\text { TEAN- } \mathrm{H}_{2} \mathrm{O}\end{array}$ & 0.25 & 80 & -11 & 25 & 0 \\
\hline
\end{tabular}

a Standard property values except all $k_{i j}=0$, Soave equation of state.

${ }^{b}$ Results for the most sensitive parameters are listed.

${ }^{c}$ All other $k_{i j}=0$.

value of the $k_{i j}$ ). The most sensitive parameters include the mixture thermal conductivity, the effective diffusion coefficient, the critical temperature and acentric factor of TEAN, and the binary interaction parameter between TEAN and water. For continuous variables, such as the mixture thermal conductivity or the effective diffusion coefficient, the parameter variations involved changing the parameter from the standard value, by the percentage shown, at every point in the calculation. Except for the $k_{i j}$, which will be considered subsequently, the variations are representative of anticipated uncertainties [18, 25], similar to past work $[2,3]$.

Uncertainties in the critical combustion pressure due to uncertainties in the thermal conductivity, the diffusion coefficient, and the acentric factor of TEAN, are comparable to the uncertainties in the parameter itself, which is similar to findings for other monopropellants [2,3]. The effect of changes in these parameters on other output variables, however, is relatively small. On the other hand, except for the critical combustion temperature, all output variables exhibit unusually strong sensitivity to uncertainties in the critical temperature of TEAN. This effect appears to be related to the vapor pressure of TEAN, with the reduced volatilities of TEAN at higher critical temperatures driving the system toward higher critical combustion pressures. The importance of TEAN for critical combustion phenomena, in spite of its relatively low concentration in the propellant, is probably due to its low volatility, which causes it to have relatively high concentrations at the liquid surface, see Fig. 3.

The high concentrations of both TEAN and water at the liquid surface are also responsible for the strong sensitivity of the critical combustion pressure to variations in the value of the binary interaction parameter between TEAN and water. Higher values of this binary interaction parameter tend to increase concentrations of TEAN in the 
liquid at the surface, acting in a manner similar to the critical temperature of TEAN. Comparable changes of all other $k_{i j}$ had a small effect, influencing output parameters less than $10 \%$, similar to past findings concerning effects of uncertainties in the $k_{i j}[2,3]$. Thus, the large increase in critical combustion pressure between Fig. 3 for all $k_{i j}=0$, and Fig. 4 for the standard $k_{i j}$, is largely due to change of the binary interaction parameter between TEAN and water.

Findings were similar using the Redlich-Kwong equation of state. Predictions were most sensitive to the binary interaction parameter between TEAN and water, and to a lesser degree to the critical temperature of TEAN.

The direct effect of the binary interaction parameter between TEAN and water on critical combustion pressure predictions is illustrated in Fig. 6. Results are illustrated for both the Soave and Redlich-Kwong equations of state. All parameters are at their standard values, except for the TEAN-water binary interaction parameter which varies as shown. The solution at the standard value of the interaction parameter is marked for the Soave equation of state: the standard critical combustion condition for the Redlich-Kwong equation of state is outside the pressure range illustrated in Fig. 6. The critical combustion pressure is relatively insensitive to the binary

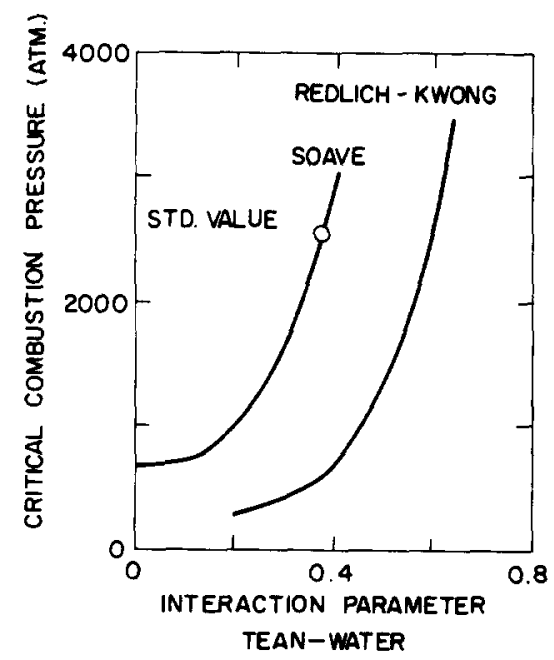

Fig. 6. Effect of the TEAN-water binary interaction parameter on the predicted critical combustion pressure. interaction parameter between TEAN and water at low values of this parameter, but becomes very sensitive in the range of the standard values. For the Soave equation of state, a $25 \%$ variation of the TEAN-water interaction parameter about the standard value would result in a $50 \%$ variation in the critical combustion pressure. This sensitivity is smaller than the sensitivity to the critical temperature of TEAN shown in Table 5; however, uncertainties in the binary interaction parameter between TEAN and water are larger than those for the critical temperature of TEAN. Thus, this interaction parameter will have to be known more accurately for definitive estimates of liquid surface temperatures and critical combustion pressures of LGP 1845 and LPG 1846.

Based on these considerations, the best estimate of the critical combustion pressure for LGP 1845 and LPG 1846 is $2500 \mathrm{~atm}$, with an uncertainty of $50 \%$. This follows from predictions using the Soave equation of state with an uncertainty of $10 \%$ for the critical temperature of TEAN, which is reasonable in view of the assessment of estimates of this property discussed earlier; and uncertainties of all other properties of $25 \%$, which is typical of past practice [2-7]. A low estimate of the critical combustion pressure would be 600 atm, based on the asymptotic of the critical combustion pressure plot for the Soave equation of state illustrated in Fig. 6. The low estimate is in the region where McBratney $[9,10]$ observed the onset of unsteady combustion waves, which often been associated with near-critical phenomena; however, the use of jelled propellants during these tests, and the absence of direct evidence concerning the onset of supercritical combustion, raises questions concerning the interpretation of these findings. The Redlich-Kwong equation of state yields critical combustion pressures greater than $4000 \mathrm{~atm}$; however, estimated binary interaction parameters for this approach are unusually high. Therefore, this finding is felt to be less reliable than results using the Soave equation of state.

In spite of the uncertainties, it seems clear that the critical combustion pressures of the HANbased monopropellants LGP 1845 and LPG 1846 are unusually high, roughly an order of magnitude higher than other liquid monopropellant and bipro- 
pellant combustion processes that have been studied [2-7]. Present uncertainties in estimates of liquid surface properties and critical combustion pressures could be reduced if liquid surface temperatures were measured; however, this is a very challenging experimental problem due to the unusually high burning rates of these monopropellants.

\section{CONCLUSIONS}

The main conclusions of the present investigation are as follows:

1. Present findings suggest unusually high critical combustion pressures for typical HAN-based monopropellants (LGP 1845 and LPG 1846), on the order of $2500 \mathrm{~atm}$ with an uncertainty of $50 \%$. This suggests that subcritical combustion and spray processes are relevant to the combustion of these monopropellants for most applications.

2. Estimates of the liquid surface properties of the present HAN-based monopropellants are unusually sensitive to the binary interaction parameter between TEAN and water, and to a lesser degree, to the critical temperature of TEAN.

3. Depending on the thermophysical and transport properties of the system, conditions at the liquid surface at the highest pressure where a liquid surface is observed (the critical combustion condition) may or may not correspond to a thermodynamic critical point.

4. The present HAN-based monopropellants exhibited relatively high liquid surface temperatures, $800-1000 \mathrm{~K}$, in the pressure range of interest (pressures greater than $100 \mathrm{~atm}$ ). This reduces polar liquid effects, which complicate the thermodynamics at lower temperatures, but increases the potential for significant liquid phase reaction near the surface, although the short residence times found under these conditions (ca. $100 \mathrm{~ns}$ ) mitigate the potential reaction effects to some degree).

It should be noted that McBratney $[9,10]$ has observed unstable combustion, which is often associated with critical combustion conditions $[2$,
3], at pressures of 600-1000 atm; therefore, present estimates may be high. New measurements are needed to reduce the uncertainties of present findings and to definitively establish the range of pressures where spray phenomena must be considered for these monopropellants.

This research was supported, in part, by the Army Research office, Contract No. DAAL0386-K-0154, under the Technical Management of D. M. Mann, and by the U.S. Army Armament Research, Development and Engineering Center, under the Technical Management of $A$. Bracuti and P.-L. Lu. The authors also wish to acknowledge useful discussions with A. Birk, E. Freedman, and W. F. McBratney of the Ballistic Research Laboratory, Aberdeen Proving Ground, Maryland.

\section{REFERENCES}

1. Lee, T.-W., Gore, J. P., Faeth, G. M., and Birk, A. Combust. Sci. Tech., 57:95-112 (1988).

2. Faeth, G. M. Combust. Flame 18:103-113 (1972).

3. Chen, L.-D., and Faeth, G. M. Combust. Flame 40:1328 (1981).

4. Allison, C. B., and Faeth, G. M. $A I A A$ J. 13:12871294 (1975).

5. Lazar, R. S., and Faeth, G. M., in Thirteenth Symposium (International) on Combustion. The Combustion Institute, Pittsburgh, 1971, p. 743

6. Canada, G. S., and Faeth, G. M., in Fourteenth Symposium (International) on Combustion. The Combustion Institute, Pittsburgh, 1973, p. 1345.

7. Canada, G. S., and Faeth, G. M., in Fifteenth Symposium (International) on Combustion. The Combustion Institute, Pittsburgh, 1975, p. 419.

8. Prausnitz, J. M., and Chueh, P. L. Computer Calculations for High-Pressure Vapor-Liquid Equilibria. Prentice-Hall, Englewood Cliffs, 1968.

9. McBratney, W. F., "Windowed Chamber Investigation of the Burning Rate of Liquid Monopropellants for Guns," report no. ARBRL-MR-03018, Ballistic Research Laboratory, Aberdeen Proving Ground, 1980.

10. McBratney, W. F., "Burning Rate Data, LGP 1845," report no. ARBRL-MR-03128, Ballistic Research Laboratory, Aberdeen Proving Ground, 1981.

11. Starling, K. Fluid Thermodynamic Properties of Light Petroleum Systems. Gulf Publishing Co., Houston, 1973.

12. Technical Data Book - Petroleum Refining American Petroleum Institute, Washington, Third Ed., Vol. 2, p. 8-55, 1976. 
13. Faeth, G. M. Prog. Energy Combust. Sci. 3:191-224 (1977); 9:1-76 (1983).

14. Faeth, G. M. Combust. Flame 8:167-174 (1967); 12:411-416 (1968).

15. Gordon, S., and McBride, B. J., "Computer Program for Calculation of Complex Chemical Equilibrium Compositions, Rocket Performance, Incident and Reflected Shocks, and Chapman-Jouguet Detonations,"' report no. NASA SP-273, NASA, Washington, 1971.

16. Dunn, P. D., and Reay, D. A. Heat Pipes. Pergamon Press, Oxford, 1976, p. 72.

17. Prausnitz, J. M., Eckert, C. A., Orye, R. V., and O'Connell, J. P. Computer Calculations for MultiComponent Vapor-Liquid Equilibria. Prentice-Hall, Englewood Cliffs, 1967, p. 18.

18. Reid, R. C., Prausnitz, J. M., and Sherwood, T. K. The Properties of Gases and Liquids. McGraw-Hill, New York, third ed., 1977.

19. Stull, D. R., and Prophet, H. JANAF Thermochemical Tables, National Bureau of Standards, Vol. NSRDSNBS 37, second ed., Washington, 1971.

20. Lyderson, A. L., Greenkorn, R. A., and Hougen, O. A. "Generalized Thermodynamic Properties of Pure Liquids," College of Engineering report no. 4, University of Wisconsin, Madison, 1955.

21. Lyderson, A. L. "Estimation of Critical Properties of
Organic Compounds," College of Engineering report no. 3, University of Wisconsin, Madison, 1955.

22. Lee, B. T., and Kesler, M. G. AIChE J. 21:510-527 (1975).

23. Verma, K. K., and Doraiswamy, L. K. Ind. Engr. Chem. Fund. 4:389-396 (1965).

24. Rihani, D. N. and Doraiswamy, L. K. Ind. Engr. Chem. Fund. 4:17-21 (1965).

25. Svehla, R. A. "Estimated Viscosities and Thermal Conductivities of Gases at High Temperatures," technical report no. R-132, NASA, Washington, 1962.

26. Reichenberg, D., DSC report no. 11, National Physical Laboratory, Teddington, England, 1971; AIChE J. 19:854-865 (1973); AIChE J. 21:181-183 (1975).

27. Wassiljewa, A. Physik Z. 5:737-742 (1904).

28. Lindsay, A. L., and Bromley, L. A. Ind. Engr. Chem. 42:1508-1511 (1950).

29. Stiel, L. I., and Thodos, G. AIChE J. 10:26-30 (1964).

30. Fuller, E. N., and Giddings, J. C. J. Gas Chromatogr. 3:222-227 (1965).

31. Fuller, E. N., Schettler, P. D., and Giddings, J. C. Ind. Engr. Chem. 58:18-27 (1966).

32. Dawson, R., Khovny, F., and Kobayashi, R. AIChE J. 16:725-729 (1970).

Received 21 September 1987; revised 18 February 1988 